\title{
UBERABA: RELAÇÕES ESCRAVAS NA CIDADE PRIMAZ (1871-1888)
}

\section{UBERABA: SLAVERY RELATIONS IN THE MAIN CITY (1871-1888)}

\author{
Júlio César de Souza ${ }^{1}$
}

Resumo: A cidade de Uberaba teve uma grande importância no cenário regional na segunda metade do século XIX, chegando a assumir a função de maior entreposto comercial da região, ligando os principais pontos econômicos do país a um vasto sertão por ser explorado. Ao realizar-se uma trajetória da história local, encontramos referências à existência de cativos. Concomitante a esse período áureo da cidade, a escravidão passava por um momento de declínio no país. Em Uberaba podemos encontrar alguns aspectos singulares da escravatura, sobretudo acoplados com o nível de desenvolvimento em que se encontrava a cidade. Por meio de produções bibliográficas acerca da temática podemos realizar um levantamento do cotidiano escravo na pequena urbe do Sertão da Farinha Podre. E desse modo reconstruir um cenário povoado por sujeitos históricos, antes excluídos, agora dotados de expressividade, que são, entre outras coisas, legítimos contribuidores na constituição da sociedade uberabense. Assim, cenas da escravidão em Uberaba poderão ser explicadas pelo desenvolvimento econômico e comercial vivenciados na cidade primaz da região onde hoje se encontra o Triângulo Mineiro.

Palavras-chave: Escravidão. Uberaba. Desenvolvimento econômico e comercial.

Abstract: Uberaba city had a great importance in the regional scenery in the second half of the XIX century, assuming the function of the greatest mercantile entrepot of the region, connecting the main economical zones of the country to an extensive backland to be explored. By making a panorama of the local history we found references to the existence of slaves. Concomitant with this golden period of the city slavery there came a decrease moment in the country. In Uberaba we can find some singular aspects of slavery, coupled with the development level in which the city was. Works published on this subject allow us to do a study on the reality of slavery at the small city of Sertão da Farinha Podre (Farinha Podre backlands) recomposing a context using historical subjects, once excluded and now having a voice. Among other things, they are legitimate contributors in composing Uberaba society. Therefore, slavery scenes in Uberaba will be explained by the economical and commercial development experienced in the main city of the region where Triângulo Mineiro is now located.

Key-words: Slavery. Uberaba. Economical and Commercial Development.

\footnotetext{
1 Professor de Educação Básica da Escola Estadual Professor Chaves/Uberaba-MG. Pós-Graduando em PROEJA no Instituto Federal do Triângulo Mineiro/Campus Uberaba. E-mail: juliokxu@hotmail.com.
} 


\section{Introdução}

O presente artigo nasceu durante a realização do Trabalho de Conclusão de Curso em Licenciatura Plena em História na Universidade de Uberaba. Num primeiro momento buscamos levantar aspectos históricos do período (1871-1888) em Uberaba, e pudemos constatar a importância regional da cidade, e por isso mesmo o cenário em que a escravidão habitou na cidade. Uberaba recebeu o título de cidade primaz, a partir do momento em que concentrou uma grande área geográfica sob a sua influência. $O$ objetivo principal desse trabalho é recuperar, ou mesmo reconstruir, cenas do cotidiano escravo na pequena urbe do Sertão da Farinha Podre, por meio de fontes bibliográficas e também de documentos encontrados no acervo sobre escravidão no Arquivo Público de Uberaba (doravante APU).

A data 13 de maio de 1888 ainda é lembrada no Brasil, sobretudo nas escolas de ensino fundamental, onde os professores narram para os seus alunos o "áureo" acontecimento da abolição da escravatura. Nessa exata data a Princesa Isabel assinou a Lei Áurea, concedendo a tão sonhada liberdade para os escravos brasileiros. O evento acontecido na corte brasileira, Rio de Janeiro, logo se espalhou para as demais províncias do país, umas receberam a notícia mais rapidamente, outras nem tanto, dependendo da sua localização, importância regional e logística. Distante da corte, em sentido do sudeste do país, um grande território pouco povoado, numa região conhecida como Sertão da Farinha Podre, numa pequena cidade, publicara-se a seguinte notícia:

Numerosos bandos de homens de côr percorriam ruidosamente a cidade, dando vivas à liberdade, ao ministério 10 de março, a Princeza Imperial Regente e ao Imperador.

De todas as estradas convergiam grupos de pretos que abandonavam as fazendas, circunvizinhas.

A 21 deste meio dia, viam-se destacados em grande número cavalleiros na estrada que desta vae, daí à cidade do Sacramento, afim de encontrar o Correio.

Pouco a pouco esse grupo foi-se aumentando com numeroso contigente de homens e mulheres a pé, que se lhe haviam ido unir.

Era indescriptível o delírio dessa multidão que ia receber dentro e pouco a confirmação de que eram, de facto, cidadãos livres. ${ }^{2}$

\footnotetext{
${ }^{2}$ Gazeta de Uberaba, 25 de maio de 1888.
} 
Essa pequena urbe era Uberaba, onde num clima de alegria a população toma ciência da Lei Áurea. O fragmento acima se tratava da publicação noticiando a abolição da escravidão no Brasil pela princesa Isabel no jornal Gazeta de Uberaba. A partir desse fato registrado num jornal da época, podemos perceber a reação popular sobre o acontecimento. Como os principais beneficiários da lei reagiram num primeiro momento, o do tomar conhecimento do fato? Um momento festivo iniciavase para os negros e abolicionistas da cidade. Porém, os ex-proprietários não tiveram motivos para participar de tal comemoração.

A lei foi promulgada em 13 de maio, e já no dia 25 do mesmo mês um jornal local publicara o fato. Como uma cidade distante da corte e considerando as precariedades do transporte, recebeu a notícia em curto espaço de tempo? Afinal, que cidade era Uberaba? Ela possuía alguma importância regional ou mesmo nacional? Havia nela escravos, e como era a escravidão nessa cidade? Para um leitor uberabense despreocupado com a historicidade do documento, a leitura dessa notícia de jornal, pode causar certo espanto. E se nessa mesma leitura, esse leitor se atentar pela data de publicação, ele certamente se assustará mais ainda, a grande maioria da população desconhece um passado uberabense, no qual temas como escravidão contribuíram para a formação histórica da cidade, seja nos aspectos econômicos, culturais, sociais e políticos.

\section{De vila a cidade primaz}

As bandeiras realizadas no Brasil no século XVIII partiram de São Paulo rumo ao interior do país, criando novos núcleos de habitantes. Sobretudo ao longo da estrada criada ligando São Paulo - Goiás. Esses viajantes encontraram uma região que denominaram como Sertão da Farinha Podre. Com a decadência das minas de ouro encontradas na região do Desemboque, a população que ali se encontrava, partiu em busca de novas conquistas, ou seja, novos territórios. E assim surgiu o arraial de Uberaba em 1816, conforme descreve Coutinho:

Uberaba começou assim. De famílias que encontraram meios propícios para progredir. De grupos de aventureiros e nômades faiscadores de ouro. De senhores, de escravos e de livres, produtos da história de então, que aqui plantaram suas sementes, que aqui desenvolveram suas raízes, que aqui fundaram sua civilização: a civilização uberabense do sertão do Brasil Central. (COUTINHO, 2000) 
A localização privilegiada do arraial fez com que o mesmo em 1856 já se elevasse a categoria de cidade. Uberaba era o ponto de parada obrigatório entre São Paulo, Goiás e Mato Grosso. E dessa forma podemos compreender a sua importância regional. Uberaba se tornara o nó que unia as duas importantes regiões econômicas brasileiras, Rio de Janeiro e São Paulo, a uma grande área agropastoril e de fronteira. E era essa região de fronteira que formava o território do Sertão da Farinha Podre. Ela estava diante de duas realidades: o principal eixo econômico do país e extensos territórios ricos em ouro, porém desabitados. Nas palavras de Lourenço:

Uberaba beneficiou-se de sua localização-chave, na intersecção entre esses dois eixos, um disposto no sentido leste-oeste (Minas - sertão) e outro no sentido norte-sul (Goiás - São Paulo). Assim, na primeira metade do século XIX, formou-se uma rede de estradas inter-regionais e interprovinciais sobre o Sertão da Farinha Podre, tendo Uberaba como nó central. (LOURENÇO, 2007)

Uberaba na segunda metade do século XIX pode ser considerada como cidade primaz, visto que a mesma assumia um caráter central na região. A cidade não possuía núcleos urbanos de grandes proporções próximos a ela. Possuía sim, nas proximidades grandes áreas com pequenos contingentes populacionais, e isoladas entre si. Uberaba polarizava a região do Triângulo Mineiro, parte de Goiás e Mato Grosso, e pode ser assim caracterizada:

(...) Uberaba era o nó de um sistema radial de estradas, o entreposto obrigatório de todos os fluxos mercantis de norte e oeste, dos territórios de Goiás e Mato Grosso. Nesta situação, os negociantes ali radicados estavam em posição favorável para extrair grande parte do excedente gerado pela economia situada no montante, por meio da manipulação das condições de mercado. Uberaba também centralizava atividades como atendimento médico, educação, acesso à justiça e administração pública. (LOURENÇO, 2007)

A primazia de Uberaba só foi ameaçada a partir do momento em que aconteceu o desenvolvimento da região. Isso aconteceu, sobretudo, no final do século XIX com o desenvolvimento progressivo da região, tendo o seu ápice com a construção da Estrada de Ferro Mogiana.

\section{Desenvolvimento econômico e urbano}

A segunda metade do século XIX marcou Uberaba pelo seu grande desenvolvimento econômico e urbano. Uberaba firmou-se como entreposto 
comercial. E juntamente com o "boom" do café no oeste paulista, acabou se beneficiando da proximidade com essa região. Dessa forma, a economia uberabense deixou a sua ligação com São João Del Rei e Formiga, passando a comunicar-se diretamente com São Paulo. E a pecuária foi o primeiro ramo da economia a ser beneficiado. A historiadora Eliane M. M. Rezende assim caracteriza:

O comércio de gado era feito através de Formiga e São João Del Rei e essas cidades mineiras abasteciam por sua vez as regiões do atual Triângulo Mineiro e as províncias de Goiás e Mato Grosso, de produtos manufaturados. Gradativamente, numa evidente racionalização de trabalho, Uberaba canalizou este comércio transformando-se em entreposto comercial para estas regiões. (REZENDE, 1992)

Nesse período podemos observar em Uberaba a criação de Engenhos de cana-de-açúcar, propriedades de fiação e tecelagem. Em 1882 foi criada a fábrica têxtil Cassu, aproveitando-se do cenário mundial de procura por algodão. E assim o algodão passou a ser industrializado no município. A força econômica de Uberaba na região pode ser compreendida no fato de metade do território do Triângulo Mineiro até 1885 ter pertencido à cidade.

Uberaba no período de 1872 a 1890 passou por um grande crescimento populacional. Passando de 8.710 habitantes para 19.174 habitantes respectivamente. Um crescimento populacional de 120\%. Esse crescimento era acompanhado também em vários outros municípios da região, no entanto, os índices uberabenses eram superiores. Segundo Lourenço:

"De acordo com o censo de 1872, a cidade dispunha de cinco advogados, seis médicos e farmacêuticos, cinco professores, 85 comerciantes e 18 funcionários públicos. Em 1880, havia, ali, uma Santa Casa de Misericórdia, um teatro, uma escola pública, um colégio particular, uma fábrica de chapéus, além de dois jornais com tipografias próprias." (LOURENÇO, 2007)

Esse trecho ilustra o grande processo de urbanização pelo qual Uberaba estava passando. Conseqüentemente houve um grande aumento das casas comerciais e do número de ruas comerciais (rua Direita, rua do Comércio, largo da matriz e outras). O crescimento urbano assumiu características centrífugas, se expandindo para as regiões denominadas: Alto da Abadia, Alto do Fabrício e Alto dos Estados Unidos. Já o Alto das Mercês e o Centro da cidade ficaram quase inalterados. As elites passaram a morar não só ao redor da Praça da Matriz, mas também no Alto da Abadia. Rezende ilustra esse apogeu urbano na cidade no seguinte trecho: em 1887, a cidade contava com três fábricas de cerveja, uma de 
queijo, uma de vinho nacional, uma extrativa de leite, uma de flores artificiais, uma de tijolos e uma de chapéus. (REZENDE, 1992)

Percebemos também nesse período uma maior concentração de pessoas morando na cidade, deixando para trás a vida rural. $E$ era também no ambiente urbano, que se encontrava a maior proporção de investimentos do município. Até 1860, 60\% dos proprietários possuíam imóveis no campo e na cidade. Em 1880 e 1890 essa porcentagem cai para 48\% e 43\% respectivamente.

Segundo ainda a historiadora, havia nesse período áureo da cidade uma expressão popular que exemplifica esse caráter de urbanização: "Paris, Rio de Janeiro, Uberaba" (REZENDE, 1992). E o interessante é que por meio dessa expressão podemos analisar o imaginário daquela época. Essa comparação de Uberaba, obedecendo a uma escala decrescente de importância e tamanho, nos permite acreditar não só na importância regional da mesma, como também na afirmativa de que a população uberabense estava ciente disso. E ainda para a autora:

À medida que a cidade se urbanizou, passou a atuar não só como centro de negócios, mas também como ponto de lazer, de convívio social, e de modernismo. Freqüentar Uberaba, significou para uma grande parte da população do município tomar um "banho de civilização". (REZENDE, 1992)

\section{Cenas da escravidão em Uberaba}

Os escravos chegaram a Uberaba no momento de fundação do arraial, junto com os seus proprietários, os geralistas. Dessa forma participaram ativamente na construção do município. Os primeiros documentos escritos que nos dão conta da existência da escravidão em Uberaba, são os registros de batizados da cidade.

A cidade de Uberaba surge no período em que se instaurava o processo de extinção do trabalho escravo no Brasil. A escravidão em Uberaba seguiu o modelo da economia local, de caráter comercial, tendo a pecuária em primeiro plano. $E$ por isso mesmo, possuiu um padrão diferenciado dos tipos de escravidão encontrados em outras regiões do país, como São Paulo e Rio de Janeiro.

Em Uberaba, sobretudo na segunda metade do século XIX, encontramos certo equilíbrio na população escrava masculina e feminina, o que indica a existência de tráfico interno de escravos e também a existência de famílias escravas, 
propiciando o aumento natural do plantel de cativos da cidade. Pode-se observar também a elevada taxa de fecundidade entre as escravas.

Podemos encontrar dados levantados por Lourenço (2007), mostrando que a partir do "boom" do café no oeste paulista, mesmo com a já promulgada Lei do Ventre Livre, o tráfico interno de escravos para o Triângulo Mineiro, em especial para Uberaba, tem um crescimento expressivo, visto que a cidade tinha uma grande ligação com a região paulista fazendo divisa com a mesma. Entretanto existem opiniões diversas:

A queda na população escrava, provavelmente, deveu-se em parte a promulgação da lei do ventre livre. Sabe-se que essa lei afetou a manutenção dos plantéis de escravos, que antes da norma era realizada por meio da reprodução natural dos cativos. Ademais, com a outorga dessa lei, todos os filhos de escravas nascidos após a sua implementação foram considerados livres. (GOMES, 2004)

A lei de 1869, que proibia a separação de grupos familiares de cativos por meio da sua comercialização, e a Lei Barão do Rio Branco, ou melhor, a Lei do Ventre Livre, que concedia a "liberdade" aos filhos recém-nascidos dos escravos, marcaram um novo período na escravidão no país. E em Uberaba não foi diferente. No entanto, é complicado definir claramente até em que ponto essas duas leis interferiram na dinâmica do escravismo local. O fato é que nas décadas de 1870 e 1880 o escravo, enquanto mercadoria perde espaço para os investimentos mobiliários que movimentavam a cidade. E como bem aponta Lourenço: o latifúndio, e não mais a escravaria, tornava-se a principal manifestação da riqueza em Uberaba. (LOURENÇO, 2007)

O principal aspecto encontrado na escravidão em Uberaba se dá na ligação com o contexto sócio-econômico. As leis de contenção do escravismo em âmbito nacional não propiciaram grandes impactos na cena uberabense, visto que, outros interesses moviam a economia no momento. No período que antecede a abolição, iniciou-se um processo de urbanização, que fez com que os investimentos econômicos se desviassem da manutenção dos plantéis cativos, para a aquisição de imóveis.

Antes da década de 1880 a principal forma de acumulação de capital era a posse de escravos. De modo que a posse de muitos escravos legitimava o status social do seu proprietário. Entretanto, com as movimentações no cenário nacional acerca da abolição da escravidão e as sucessivas leis criadas que cerceavam a livre 
manutenção da mesma, coincidiram com o momento em que Uberaba vivia um intenso processo de urbanização e conseqüentemente de crescimento populacional. É necessário mencionar que, em 1850 com a proibição do tráfico internacional de escravos para o Brasil, o escravo alcançou maiores valores comerciais. Nas duas últimas décadas que antecederam a abolição, isso foi diferente. O preço médio do escravo cai na medida em que o ano de 1888 foi se aproximando, e junto dele, "as visões da liberdade".

\section{Famílias escravas}

A existência de núcleos familiares entre os cativos em Uberaba podem ser verificadas no acervo sobre escravidão no APU. Bem como temos alguns trabalhos produzidos sobre a presente questão. Em "De batuques e trabalhos" podemos não só perceber essa existência, como também, a partir dos apontamentos levantados por Ribeiro Júnior, conduzir a nossa discussão acerca das famílias escravas na cidade. Em suas palavras:

Ao examinarmos algumas fontes atinentes à história da cidade de Uberaba
no século XIX, notamos que são fortes as evidências da existência de
organização familiar entre os escravos ali residentes nesta cidade,
representando um dos fatores importantes na elaboração e articulação de
suas vidas como cativos, e, para além dessa condição, funcionando
também como meio de construção de identidades entre os escravos e os
libertos, fornecendo-lhes instrumentos de luta por uma vida melhor,
calcadas em suas experiências no cativeiro. (RIBEIRO JÚNIOR, 2001)

As evidências de que existiram famílias escravas em Uberaba podem também ser vistas em outras obras que não privilegiam a escravidão como o seu foco central. Pode ser visto no trabalho de Rezende: em Uberaba, um próspero fazendeiro possuía nesse período, entre 10 a 15 escravos, sendo que alguns chegavam a possuir de 20 a 25 escravos. (REZENDE, 1992) Num plantel de escravos considerável como a autora nos aponta, podemos inferir que nas senzalas desses proprietários, a existência de laços de família entre os cativos fosse bem provável. Ainda mais se pensarmos que a partir de 1850, a Lei Euzébio de Queiróz aboliu o tráfico de escravos para o Brasil, fazendo com que a migração interna entre as províncias fosse estimulada, e ainda havia na reprodução natural do plantel, não só 
uma continuidade da existência de mão-de-obra escrava, como também um estímulo a constituição desses laços dentro das senzalas.

A maioria da população escrava encontrou-se dividida pelas pequenas e médias propriedades. Ao contrário dos grandes proprietários, a maioria possuiu entre um a cinco cativos. Isso não impossibilitou a existência de laços familiares entre os cativos. Outro fato que diferentemente, pode ter contribuído para a constituição desses laços foi o equilíbrio entre os sexos dos cativos, durante grande parte da escravidão em Uberaba. No entanto esse equilíbrio não foi natural, na medida em que existia um aumento da população escrava masculina por meio do tráfico negreiro, a formação de enlaces entre os negros, possivelmente possibilitou novamente um equilíbrio de sexos entre os escravos da cidade. Ao posto que o tráfico internacional de escravos já estivesse proibido, esse equilíbrio entre os escravos pode ser explicado não só pelo tráfico interprovincial, como também pela reprodução natural da escravaria, reforçando a existência de famílias escravas no município. Outra contribuição para a formação de famílias escravas, segundo Gomes (2004, p.2), é o tipo de economia que existiu em Uberaba, uma vez que uma economia voltada para a criação de gado e agricultura de subsistência necessitava de trabalhos mais amenos, se comparado com outros tipos de economia, sobretudo em áreas de mineração.

Podemos perceber na grande parte dos estudos atuais sobre famílias escravas, uma contraposição a alguns estudos que contam da inviabilidade das formações de laços de família entre os negros no cativeiro. ${ }^{3}$ Seja no Brasil ou mesmo nos Estados Unidos, estudos de décadas anteriores consideravam a vida familiar dos escravos inexistentes, ou mesmo precárias. No entanto, posteriormente com novas linhas historiográficas, encontramos inúmeros trabalhos que nos dão conta, não só da existência de grupos familiares, como também da importância da formação dessas famílias no contexto da sociedade brasileira. Uma verdadeira

\footnotetext{
${ }^{3}$ A discussão sobre uma nova forma de enxergar a escravidão no Brasil pode ser vista em: ROCHA, Cristiany Miranda. Histórias de famílias escravas: Campinas, século XIX. Campinas: Editora da Unicamp, 2004. Ver também: RIBEIRO JÚNIOR, Florisvaldo Paulo. "De batuques e trabalhos" Resistência negra e a experiência do cativeiro - Uberaba, 1856/1901. Tese de mestrado em História. PUC: São Paulo, março de 2001.
} 
tarefa de desmistificação sobre a escravidão no Brasil teve início em meio a essas novas discussões.

Retomemos o período privilegiado nesse trabalho: 1871-1888. O ponto inicial é a promulgação da Lei do Ventre Livre em 1871. A presente lei tinha antes de mais nada como foco, conceder liberdade aos filhos dos escravos nascidos a partir da mesma data. Anteriormente. outra lei conhecida simplesmente como Lei de 1869, já havia proibido a separação de grupos familiares cativos por meio de sua comercialização. Franco Netto analisando a formação de grupos de famílias escravas em Guarapuava, chegou à seguinte conclusão:

Parece-nos que no período entre as décadas de 1840 e 1850 a pressão
quanto ao fim do tráfico atlântico de escravos, bem como o fim do tráfico
internacional de escravos, poderia estar estimulando os casamentos na
localidade. Entretanto, já no período seguinte, a promulgação da lei de
1869 , que proibia a separação de famílias escravas, provavelmente inibiu
ações nesse sentido, como também o intenso movimento do tráfico interno,
principalmente na década de 1870 que tornava os casamentos mais difíceis.
Porém, em termos de número de registros de casamentos, não nos parece
que as leis que determinaram a interrupção do tráfico, bem como a inibição
das uniões entre os escravos, influenciaram sobre as uniões entre os
escravos em Guarapuava, pelo menos em termos oficiais. (FRANCO
NETTO, 2007)

Em Uberaba, num primeiro momento, de acordo com Ribeiro Júnior (2001, p.98-143) podemos perceber uma grande diminuição na presença de crianças nos inventários, com a aplicação das leis citadas. Gomes (2004, p.1-11), num trabalho demográfico sobre a escravidão em Uberaba observa uma queda na população cativa no período analisado. Ela acredita na Lei do Ventre Livre como a principal responsável por essa diminuição no plantel cativo da cidade. Assim: "sabe-se que essa lei afetou a manutenção dos plantéis de escravos, que antes da norma era realizada por meio da reprodução natural dos cativos. Ademais, com a outorga dessa lei, todos os filhos de escravas nascidos após a sua implementação foram considerados livres." (GOMES, 2004)

A análise da referida autora nos possibilita perceber que a proporção do crescimento de escravos não acompanhou o crescimento da população livre na cidade. No entanto, não nos possibilita afirmar a respeito do impacto da Lei do Ventre Livre sobre os dados por ela tabelados. Assim, não podemos saber até em que ponto essas crianças filhas de escravos impactaram nos dados encontrados nos censos realizados na cidade. 
Por outro lado Ribeiro Júnior (2001, p.98-143) observa um expressivo número de alforrias concedidas aos filhos de escravos não abençoados pela lei de 1871 . Que de certa forma para ele era uma estratégia de dominação senhorial. Garantindo assim, não só a permanência dos pais escravos nas senzalas, mas também um sentimento de gratidão para com o seu senhor. De igual forma, o autor também encontrou registros de venda de famílias de escravos anteriores a lei de 1869, que mantinham juntos o grupo familiar. Ele percebe ainda que a lei de 1871 teve rápida aplicação em Uberaba. Outra implicância trazida por esta lei foi à possibilidade de esconder a idade das crianças nos inventários, e dessa forma burlar a lei.

Outra questão que pode ser identificada são as concessões de liberdade. Essas, muitas vezes dirigidas aos menores vinham sucedidas em alguns casos, de reconhecimento de paternidade. Demonstrando uma prática habitual da época, o concubinato, praticado pelos proprietários de escravas. Este era mais uma esperança de liberdade, visto que a grande parte das escravas ligadas ao seu proprietário por concubinato gozava de certas regalias e enxergavam em seus filhos os seus sonhos de liberdade.

Em busca da presença da família escrava nos documentos oficiais de Uberaba de 1871 a 1888, encontramos no APU um rico acervo de registros de casamentos, registros de batismos e processos criminais sobre a temática escravidão. Por meio desses documentos pudemos juntar algumas pistas que nos levam a remontar um cotidiano das famílias de escravos na pequena urbe do Sertão da Farinha Podre. Ao analisarmos os registros de batizados disponíveis para consulta no APU, deparamos com livros de registros da cerimônia do batizado em que as crianças escravas eram registradas juntamente com as demais crianças brancas, no entanto com uma marcação em forma de um " $X$ ", podemos identificar que aquele registro era de uma criança escrava recém batizada. Da mesma forma essa identificação pode ser encontrada nos registros matrimoniais. Nestes, podemos ainda perceber um relato mais simplificado em se tratando de um casamento envolvendo escravos, sejam os dois noivos escravos ou um escravo e o outro liberto. Nota-se a citação do nome do escravo, quase sempre um nome simples sem sobrenome, sucedido pelo nome do seu proprietário. Diferentemente dos registros de casamentos entre pessoas livres brancas, nos quais a presença dos nomes dos 
pais dos noivos é imprescindível, e da mesma forma a indicação da origem da família dos noivos, ou seja, de qual freguesia eles eram oriundos.

Nos processos criminais, encontramos dois casos em específico que puderam nos auxiliar na discussão sobre o cotidiano escravo desses núcleos familiares na cidade. O primeiro caso, Alexandrina, uma criança negra filha de escravos, nascida sobre a tutela da Lei do Ventre Livre, viu-se punida por cometer um crime de roubo, que pelas entrelinhas podemos identificar como mascaramento de uma realidade de exploração do trabalho de filhos de escravos. Depois encontramos Maria Rita, escrava, mulher negra, mãe, que fugiu da propriedade do seu senhor com o filho nos braços, deixando para trás um presente de castigos físicos. Trazendo na fuga uma gama de sentimentos, um verdadeiro misto de ódio, rancor, amor, esperança e desejo de liberdade. Se forem esses os sentimentos vivenciados por essa mulher, nós realmente não sabemos. O que sabemos é que o seu grito de revolta foi ouvido por nós, e agora continua ainda a ser ouvido...

Temos agora não mais uma preocupação em constatar a existência de famílias escravas em Uberaba, mas sim tentar resgatar algumas cenas desse cotidiano escravo vivenciado por esses sujeitos esquecidos pela história local. Lembrando de Ginzburg (1989, p.143-179), não podemos deixá-lo de lado com seu o paradigma indiciário, as pistas são muitas. E dessa forma uma análise maior dos processos crimes acima citados poderá nos auxiliar no objetivo de levantar mais cenas desse rico cotidiano vivenciado na pequena urbe do Sertão da Farinha Podre.

\section{REFERÊNCIAS}

COUTINHO, Pedro dos Reis. História dos Irmãos Maristas em Uberaba. Uberaba: Arquivo Público de Uberaba; Belo Horizonte: Centro de estudos maristas, 2000.

FRANCO NETTO, Fernando. Relações entre senhores e escravos em área voltada para o abastecimento interno - Guarapuava século XIX. XXIV Simpósio Nacional de História, ANPUH. São Leopoldo: Unisinos, 2007.

GINZBURG, Carlo. "Sinais - Raízes de um Paradigma Indiciário". In: Mitos, Emblemas e Sinais. São Paulo: Companhia das Letras, 1989. pp.143-179.

O queijo e os vermes. São Paulo: Cia das Letras, 1991 
GOMES, Alessandra Caetano. Os Pretos forros do Sertão da Farinha Podre: Um caso de equilíbrio entre os sexos dos libertos de Uberaba-MG 1840-1888. XIV Encontro Nacional de Estudos Populacionais, ABEP. Campinas: Unicamp, 2004.

LOURENÇO, Luís Augusto Bustamante. Das Fronteiras do Império ao Coração da República: o Território do Triângulo Mineiro na Transição para a Formação SócioEspacial Capitalista na Segunda Metade do Século XIX. São Paulo, 2007. 306p. Tese (Doutorado em Geografia Humana) - Universidade de São Paulo.

REZENDE, Eliane M. Márquez. Uberaba: uma trajetória sócio-econômica - 18111910. Uberaba: Edição APU, 1992.

RIBEIRO JÚNIOR, Florisvaldo Paulo. “De batuques e trabalhos” - Resistência negra e a experiência do cativeiro - Uberaba, 1856/1901. Tese de mestrado em História. PUC: São Paulo, março de 2001.

A conquista da liberdade: cenas do cotidiano uberabense nas últimas décadas da escravidão no Brasil. Trabalho de monografia. Universidade Federal de Uberlândia: Uberlândia, 1997.

ROCHA, Cristiany Miranda. Histórias de famílias escravas: Campinas, século XIX. Campinas: Editora da Unicamp, 2004.

Recebido para publicação em: 28/09/09

Aceito:30/01/10 